\title{
A Educação em Saúde e o Trabalho com Adolescentes em Conflito com a Lei
}

Health Education and Working with Adolescents in Conflict with the Law

Educación en Salud y Trabajo con Adolescentes en Conflicto con la Ley

\section{LUCIANO APARECIDO PEREIRA JUNIOR ${ }^{1}$, REGINA CÉLIA DE SOUZA BERETTA ${ }^{2}$}

${ }^{1}$ Universidade de Franca

${ }^{2}$ Universidade de Franca

\begin{abstract}
RESUMO: A educaşão em saúde e a cultura da paz, são ferramentas essenciais para o trabalho dentro da promocão da saúde. Deste modo, este estudo busca compreender o quanto a educação em saúde, dentro da promocão da saúde, pode ser um instrumento essencial no trabalbo com adolescentes em conflito com a lei. A pesquisa contou com a participacão de doze adolescentes em cumprimento de Medida Socioeducativa de Liberdade Assistida, que participaram de uma oficina de Promocão da Saúde e Cultura da paz. e dos grupos focais, além dos seus pais e responsáveis que foram entrevistados e da análise dos Planos Individuais de Atendimento. Os dados foram analisados por meio da perspectiva teórico-metodológica do Construcionismo Social. Foi observada a necessidade de que as politicas públicas dialoguem efetivamente entre si e que os profissionais estejam preparados para esta modalidade de atendimento. A promoção da saúde só é efetiva pela intersetorialidade e interdisciplinaridade da rede.

CULTURA DA PAZ. EDUCAÇÃO EM SAÚDE. PROMOÇÃO DA SAÚDE. SAÚDE DO ADOLESCENTE.
\end{abstract}

\begin{abstract}
Health education and the culture of peace are essential tools for working within health promotion. Thus, this study seeks to understand bow health education, within bealth promotion, can be an essential tool in working with adolescents in conflict with the law. The research included the participation of twelve adolescents in compliance with the Socio-Educational Measure of Assisted Freedom, who participated in a Health Promotion and Culture of Peace workshop and focus groups, in addition to their parents and guardians who were interviewed and the analysis of Individual Plans Service. The data were analyzed using the theoretical and methodological perspective of Social Constructionism. There was a need for public policies to effectively dialogue with each other and for professionals to be prepared for this type of service. Health promotion is only effective due to the intersectoriality and interdisciplinarity of the network.

CULTURE OF PEACE. HEALTH EDUCATION. HEALTH PROMOTION.

ADOLESCENT HEALTH.
\end{abstract}

Os autores cedem à Revista Internacional Educon os direitos de primeira publicação do presente artigo. Aplicam-se os termos de uma licença Creative Commons Atribuição 4.0 Internacional (CC BY 4.0), que permite o uso irrestrito, a distribuição e a reprodução em qualquer meio desde que a publicação original seja corretamente citada. 


\begin{abstract}
RESUMO: La educación para la salud y la cultura de paz son herramientas fundamentales para trabajar en la promoción de la salud. Así, este estudio busca comprender cómo la educación en salud, dentro de la promoción de la salud, puede ser una berramienta fundamental en el trabajo con adolescentes en conflicto con la ley. La investigación contó con la participación de doce adolescentes en cumplimiento de la Medida Socioeducativa de Libertad Asistida, quienes participaron en un taller de Promoción de la Saludy Cultura de Pazy grupos focales, además de sus padres y tutores que fueron entrevistados y el análisis de Planes Individuales. Servicio. Los datos fueron analizados desde la perspectiva teórica y metodológica del Construccionismo Social. Era necesario que las politicas públicas dialogaran eficarmente entre si y que los profesionales estuvieran preparados para este tipo de servicio. La promoción de la salud solo es efectiva debido a la intersectorialidad e interdisciplinariedad de la red.
\end{abstract}

CULTURA DE PAZ. EDUCACIÓN PARA LA SALUD. PROMOCIÓN DE LA SALUD. SALUD ADOLESCENTE.

\title{
Introdução
}

A educação em saúde se demonstra como uma ferramenta essencial, quando se aborda a promoção da saúde da população. A educação possibilita ampliar espaços de construção e diálogo, e engaja os sujeitos dentro do processo, por meio de uma participação social ativa e participativa. Ao abordar estes dois conceitos, é preciso compreender a perspectiva teórica de ambos e o que a proposta desta junção contém como objetivo dentro da promoção da saúde, mediante a população adolescente em conflito com a lei.

O Brasil ainda é um dos países mais desiguais do mundo e possui índices alarmantes de homicídios de adolescentes. A cada dia são assassinadas 31 crianças e adolescentes, no país, com características específicas: meninos, negros e moradores de favelas. Esses dados mostram que o Brasil é o país com maior número absoluto de adolescentes mortos no mundo (Unicef, 2015).

Outro quesito importante da realidade da população adolescente no país é a educação. Dados apontam que o número de adolescentes fora da escola e sem trabalho tem crescido cada vez mais. Esta exclusão escolar que ocorre e a evasão recorrente possuem aspectos peculiares, pois a maioria destes adolescentes é pobre, negra, indígena e quilombola. E aponta para um cenário, em que muitos deixam de estudar para poder trabalhar e contribuir para a renda familiar (Unicef, 2015, Ibge, 2017).

Estas e outras vulnerabilidades que permeiam a vida dos adolescentes alimentam um ciclo de violação de direitos constante, o que leva a uma reprodução da violência sofrida e do cometimento do ato infracional. As medidas socioeducativas são aplicadas pela autoridade judicial mediante o ato infracional cometido pelo adolescente, que não possuem caráter punitivo e repressivo, mas sim educativo, contemplando um processo de corresponsabilização e não a culpabilização do indivíduo e sua família. Estas medidas podem ser de advertência, reparação de danos, prestação de serviços à comunidade, liberdade assistida, semiliberdade e internação. Ambas as medidas socioeducativas configuram um trabalho conjunto entre o Governo Federal, os estados e os municípios para que todas as demandas desta população sejam atendidas (Brasil, 1990).

O Centro de Referência Especializado de Assistência Social (CREAS) integra o Sistema Único de Assistência Social (SUAS), sendo um serviço de proteção social especial de média complexidade, atendendo indivíduos e famílias em situação de vulnerabilidade e vítimas de violência. $\mathrm{O}$ atendimento ocorre por meio do Serviço de Proteção e Atendimento Especializado a Famílias e Indivíduos (PAEFI), garantindo orientação, proteção e acompanhamento às pessoas. Como destaca a Política Nacional de Assistência Social (PNAS), o atendimento neste serviço visa também o convívio familiar e comunitário, atendendo as demandas geradas pelas violações de direitos, como as medidas socioeducativas de meioaberto, como a Liberdade Assistida (LA), aqui estudada, e a Prestação de Serviço à Comunidade (PSC), tendo por objetivo à proteção integral dos adolescentes em conflito com a lei (Brasil, 2004). 
Este estudo possui fragmentos de uma pesquisa desenvolvida entre agosto e outubro de dois mil e dezenove, com doze adolescentes do sexo masculino em cumprimento de Medida Socioeducativa (MSE) de Liberdade Assistida (LA), no Centro de Referência Especializado de Assistência Social (CREAS), em uma cidade de médio porte localizada no interior do Estado de São Paulo. A temática promoção da saúde e cultura da paz e sua relação com as medidas socioeducativas tem sido pouco discutida nos meios acadêmicos. Deste modo, este estudo pode contribuir para beneficiar socialmente e teoricamente as pesquisas que possam ser desenvolvidas e que abordem as medidas socioeducativas, e especial, as de meio aberto.

\section{A educação em saúde, a cultura da paz e os adolescentes em conflito com a} lei

\subsection{A educação como "construtora" de sujeitos}

A educação não deve estar limitada ao processo de ensino-aprendizagem somente, nem estar associada apenas ao ambiente escolar. A educação deve ser vista como um processo sociocultural em que os indivíduos vão construindo, por meio de suas vivências, diversas formas de conhecimento, que dão a ciência diversos conteúdos a serem estudados.

$\mathrm{Na}$ perspectiva freiriana podemos tomar a educação como um processo de humanização. Freire aponta que a incumbência dos docentes além de fazer com que o aluno aprenda, traz consigo o cuidado antropológico, para que o humano se manifeste nos indivíduos (Freire, 1970). E é sobre esta segunda perspectiva, apontada pelo teórico, que o processo de educar em saúde se constitui como uma ferramenta essencial no cuidado à saúde de adolescentes em conflito com lei. Os docentes não se limitam somente ao cunho pedagógico, mas àqueles que se colocam em posição de ensinar e de compreender a humanidade no outro, num processo de empoderamento, circundado pela criação de um espaço dialógico em que todos possam se manifestar e se expressar.

Conceituar à educação pode ser um grande desafio metodológico-científico. Ecco e Nogaro (2015, p. 3526), descrevem a compreensão de educação e humanização de uma forma clara, sendo que:

Educação e humanização são termos indicotomizáveis, pois educar, em síntese, objetiva formar e "trans-formar" seres humanos, valorizando processos de mudança dos sujeitos, atualizando suas potencialidades, tornando-os humanos. Ademais, concebemos o ato pedagógico como um ato de educar; e o trabalho do educador efetiva-se com e entre seres humanos.

O ser humano é sempre um ser inacabado e em constante construção. Ele se transforma constantemente no decorrer do seu desenvolvimento. Neste sentido, "educar é promover o outro" (Ecco \& Nogaro, 2015, p. 3526), e promover saúde é possibilitar ao outro formas e meios que garantam a qualidade de vida e o bem-estar. Educar em saúde, então é promover ao outro a saúde e garantir aos sujeitos o acesso a ela como direito e política pública constituída.

\subsection{A saúde como campo de ação da educação}

A saúde, como estabelece a Organização Mundial de Saúde (1947), pode ser considerada como "um completo estado de bem-estar físico, mental e social e não apenas a ausência de doença ou enfermidade". Dentro desta prática pode-se compreender o modelo holístico, embora alguns teóricos discordem deste entendimento, na concepção do ser humano em sua integralidade. E a partir dessa compreensão, biopsicossocial do indivíduo, podemos entender o processo de uma educação humanizadora e saudável. 
A promoção da saúde pode ser conceituada como um processo de capacitação comunitária que tem como objetivo a melhoria da qualidade de vida e da saúde das pessoas, envolvendo todos os atores dentro do controle deste processo. Para que se alcance o bem estar biopsicossocial e espiritual é preciso que as necessidades e demandas sejam atendidas e que isto reflita de modo favorável no território onde os indivíduos vivem (Ottawa, 1986).

A educação em saúde atrelada a promoção da saúde, pode ser abordada em cartas e declarações internacionais e dentro da Política Nacional de Promoção da Saúde (PNPS), no Brasil.

A Carta de Ottawa (1986) representa um marco significativo para a promoção da saúde e para a inserção da educação em saúde dentro do cenário mundial, buscando a construção de políticas públicas saudáveis por meio de aspectos essenciais como a capacitação, em que estabelece a necessidade de:

Alcançar a equidade em saúde é um dos focos da promoção da saúde. As ações de promoção da saúde objetivam reduzir as diferenças no estado de saúde da população e assegurar oportunidades e recursos igualitários para capacitar todas as pessoas a realizar completamente seu potencial de saúde (Ottawa, 1986, p. 1).

Dentro do cenário brasileiro, tendo como base a carta acima citada, tem-se a Política Nacional de Promoção da Saúde (PNPS), que em seus eixos operacionais, possui estratégias para se concretizar a aplicação da política. Dentro dela a educação e a formação são pautadas "enquanto incentivo à atitude permanente de aprendizagem sustentada em processos pedagógicos problematizadores, dialógicos, libertadores, emancipatórios e críticos" (Brasil, 2014).

Por meio da promoção da saúde pode-se pensar a cultura da paz e a prevenção de violências, sendo esta uma responsabilidade de cada ator social, reduzindo assim os riscos de violência e possibilitando a colaboração e autonomia de cada cidadão, pensando no respeito à vida e nos direitos humanos, num espaço de colaboração e diálogo, previsto na PNPS (Brasil, 2014).

A cultura da paz deve ser abordada como uma ferramenta essencial para que os discursos permeados pela violência possam ser permeados pela paz. Dupret (2002, p. 91) destaca que "construir uma cultura da paz envolve dotar as crianças e os adultos de uma compreensão dos princípios e respeito pela liberdade, justiça, democracia, direitos humanos, tolerância, igualdade e solidariedade". Neste sentido, a participação social se torna essencial para que se garanta tal cultura e para que esta se fundamente como eixo a ser abordado dentro da promoção da saúde.

\subsection{A educação em saúde e o adolescente em conflito com a lei}

A educação em saúde pode chegar aos adolescentes em conflito com a lei, por diversos meios. No entanto, ela tende a encontrar ali barreiras estabelecidas pelas vulnerabilidades existentes que afetam diretamente essa população e as suas famílias.

O número alto de evasão escolar neste público, os problemas de aprendizagem, as dificuldades em conseguir vagas no ensino público regular, as relações familiares fragmentadas e rompidas, a presença da violência nos territórios, além, dos aspectos transgeracionais, em que os pais também se ausentaram cedo da escola, além do uso de drogas e do crime, cometido pelos pais, e agora refletido nos adolescentes por meio do consumo e do ato infracional, sendo neste caso, o tráfico o mais comum, compõem alguns dos dificultadores da educação em saúde (Alvarenga, 2012, Fonseca, Sena, Santos, Dias \& Costa, 2013).

Existe ainda o não acesso aos serviços, em especial a saúde, visto que os adolescentes pouco procuram este espaço e não há um movimento de ida e integração desse público aos serviços. O vínculo mais forte estabelecido se dá com a assistência social, visto que é no CREAS que cumprem as medidas socioeducativas, no entanto, por um motivo até então obrigatório. Não havendo um movimento espontâneo de uso e acesso a estes espaços. 
Este estudo busca compreender, o quanto a educação em saúde, dentro da promoção da saúde, pode ser um instrumento essencial no trabalho com adolescentes em conflito com a lei.

\section{Metodologia}

O estudo aqui apresentado possui fragmentos de uma pesquisa desenvolvida em dois mil e dezenove, com doze adolescentes em cumprimento de Medida Socioeducativa (MSE) de Liberdade Assistida (LA), no Centro de Referência Especializado da Assistência Social (CREAS), em um município no interior do Estado de São Paulo. A pesquisa foi autorizada pelo judiciário da Vara da Infância e da Juventude e aprovado pelo comitê de ética da Universidade de Franca, com o CAAE 03384018.9.0000.5495.

A pesquisa contou com algumas etapas, havendo inicialmente uma revisão integrativa, que como destaca Souza, Silva e Carvalho (2010) é uma ferramenta de busca de dados contidos na literatura, composta por um processo de seis fases, em que se estabelece o conhecimento atualmente existente na literatura sobre um assunto específico.

Inicialmente houve a elaboração da pergunta norteadora do trabalho (1 $1^{a}$ etapa): "É possível que a cultura da paz auxilie na prevenção do ato infracional e da violência?". Posteriormente, houve a busca ou amostragem na literatura (2a etapa), nas bases de dados Scielo, Pepsic, Redalyc, Google Acadêmico e documentos oficiais do governo brasileiro e internacionais conforme os seguintes descritores em saúde: adolescente, promoção da saúde e educação em saúde. Dentro da terceira etapa, estabelece-se a coleta de dados, em que estes foram escolhidos perante o tema a ser abordado e as relações que possuem no campo da saúde. Sendo utilizados vinte e dois artigos, três livros e dezoito documentos nacionais e internacionais, pertinentes à temática, que foram selecionados por meio da leitura de seus resumos. Foram utilizados artigos e documentos internacionais, em espanhol, que retrataram a América Latina e em inglês, com ênfase na Organização Mundial de Saúde (OMS). Posteriormente houve uma análise crítica dos estudos ( $4^{a}$ etapa), além de uma leitura atenta às informações, baseando-se nas evidências coletadas sobre a temática e a atualidade. Em seguida, a discussão dos dados coletados ( $5^{a}$ etapa) e a apresentação da revisão ( $6^{a}$ etapa) como consistem a introdução e a revisão de literatura deste estudo.

Posteriormente, a pesquisa de campo contou com algumas etapas essenciais no processo, sendo elas a intervenção (oficina), os grupos focais e as entrevistas por pauta com os pais e responsáveis. A pesquisa de campo, como aponta Gil (2008), ocorre com a integração do pesquisador a pesquisa, como parte dela e em contato com os fenômenos a serem observados, relatando a realidade tal como ela é e se apresenta.

A seleção dos adolescentes se deu por critérios de inclusão e exclusão, como a idade entre 14 e 17 anos e estar cumprindo a modalidade de Liberdade Assistida. Houve uma reunião com os adolescentes que se enquadravam nestes critérios, a apresentação do projeto e doze deles se dispuseram a participar.

Após a reunião houve uma Oficina sobre Promoção da Saúde e Cultura da Paz, a fim de inserir os adolescentes à temática proposta pela pesquisa. Uma oficina pode ser caracterizada como um meio de tratar conhecimentos de modo inter-relacionado e correlacionado, envolvendo os integrantes em um processo ativo na construção de seu próprio conhecimento e na exposição de suas experiências frente à temática abordada (Marcondes, 2008). A oficina teve a duração de uma hora e meia, para que por meio do diálogo entre os adolescentes eles pudessem conhecer e construir conhecimentos por meio da temática proposta. Esta intervenção contou com a apresentação da cultura da paz e do seu significado - mediante o uso de recursos audiovisuais e impressos - e da sua inserção dentro da promoção da saúde, havendo no fim uma discussão sobre o tema e a relação destes aspectos com os atos infracionais cometidos.

Em seguida foram realizados seis grupos focais, com seis categorias pré-estabelecidas, abordando a família, a violência, os direitos e deveres do adolescente, as relações sociais, os serviços disponíveis no território e a cultura da paz. Por fim, foram realizadas entrevistas com pais e responsáveis e a análise do Plano Individual de Atendimento (PIA), que é um documento construído pelo técnico de referência do 
adolescente - comumente desempenhado por um assistente social -, o adolescente e os seus familiares, a fim de que ali esteja o histórico de vida do adolescente, as propostas do atendimento e as perspectivas futuras do adolescente.

A análise se deu por meio da perspectiva do Construcionismo Social, que como salienta Rasera e Japur (2001), pode ser utilizado como um referencial teórico-metodológico, pautado no cotidiano e na construção de conhecimentos, e uma análise incessante e atenta a cada informação contida tanto nas transcrições, possibilitada pelas gravações, quanto no PIA e base de dados da literatura.

\section{Resultados e Discussão}

O ato de educar em saúde é possibilitar espaços para que os conhecimentos possam ser construídos e para que os indivíduos possam se manifestar acerca de suas experiências e vivências. É no encontro de diversas realidades que o conhecimento se dá, visto que, ele só é possível a partir do momento em que, as pessoas se colocam em posição de ensinar e aprender (Falkenberg, Mendes, Moraes $\&$ Souza, 2014).

A Oficina de Promoção da Saúde e Cultura da Paz, que se deu em um único encontro, viabilizou a integração junto aos adolescentes sobre os conceitos de cultura da paz e de promoção da saúde, que foram observados de forma prática por cada adolescente em seu cotidiano. Assim, a oficina possibilita construir conhecimentos ainda desconhecidos e possibilita que novas visões de mundo sejam criadas a partir desta vivência. A educação em saúde, além da oficina, integrou os grupos focais e suas categorias, visto que, não há saúde, sem que haja uma educação voltada para esta questão. O trabalho contou com uma análise centrada no Construcionismo Social, possibilitando que os adolescentes fossem produtores de todo e qualquer conhecimento ali construído.

Uma diferenciação importante deve ser feita quanto à educação atrelada à saúde. A educação em saúde, conforme estabelece o Ministério da Saúde (Brasil, 2006) deve ser vista como um processo educativo que visa à construção de conhecimentos por meio da participação ativa da população, aumentando a autonomia das pessoas quanto ao cuidado e propondo a interação constante com profissionais e gestores a fim de que se garanta a atenção a todas as necessidades apresentadas. Já o conceito de educação na saúde, como descrito na Biblioteca Virtual em Saúde (BVS) corresponde ao processo de produção e sistematização dos conhecimentos, partindo de um processo teórico e formal, como as práticas de ensino, as diretrizes didáticas e a orientação curricular (Brasil, 2009). Deste modo, a educação em saúde está centrada na participação social, influenciada pelos processos socioeconômicos e culturais que envolvem a população, na construção de conhecimentos, enquanto, a educação na saúde, parte do pressuposto de estruturação e regularização do papel da educação dentro do âmbito da saúde.

Machado e Wanderley (n.d., p. 6), destacam que:

A Educação Permanente em Saúde (EPS) parte do pressuposto da aprendizagem significativa e problematizadora, propondo estratégias que possibilitam a construção coletiva, além de nortear caminhos para uma relação dialógica e horizontal, em que cada protagonista do SUS (trabalhadores, usuários e gestores) possa compartilhar, ensinar e aprender, construir e desconstruir concepções, ideias e conceitos acerca da saúde, de sua produção e operação e de seus papéis.

No entanto, o ato de educar em saúde não deve se limitar somente aos preceitos do SUS, mas devem ser ampliados às diversas outras políticas públicas existentes, como assistência social, educação, cultura, esporte e lazer, por exemplo, além da segurança pública, visto que quando a promoção da saúde é abordada, ela pressupõe garantir a qualidade de vida e o bem-estar da população, e na saúde dos indivíduos, diversos Determinantes Sociais da Saúde (DSS) interferem, como as condições 
socioeconômicas, habitação, saneamento básico, alimentação, emprego e demais questões essenciais para a sobrevivência humana (Ribeiro, Aguiar \& Andrade, 2018).

A Educação Popular em Saúde (EPS), enquanto política pública estabelecida em 2013, conforme a Política Nacional de Educação Popular em Saúde (PNEP-SUS) propõe a promoção, a proteção e a recuperação, por meio do diálogo entre a diversidade de saberes, valorizando os saberes populares, a ancestralidade, a produção de conhecimentos e a inserção destes aspectos no Sistema Único de Saúde (SUS). A aplicabilidade desta política possui quatro eixos importantes, sendo eles, a participação social, controle social e gestão participativa; formação, comunicação e produção de conhecimento; cuidado em saúde; intersetorialidade - trabalho entre setores - e diálogos multiculturais (Brasil, 2017).

Educar em saúde, como destaca Falkenberg et al. (2014), exige do profissional um olhar ampliado para as instâncias do sujeito e um conhecimento amplo e próximo do território, para que se possam ser observadas as realidades com que convivem. A educação em saúde não deve operar em espaço fechado, mas ir de encontro ao público e às suas demandas. Promover um espaço participativo em que os indivíduos se tornem agentes e atores sociais é essencial, para que o trabalho no território possa obter resultados, mediante um processo democrático em que haja justiça social.

A Oficina de Promoção da Saúde e Cultura da Paz possibilitou que os adolescentes tivessem o primeiro contato com os termos e quão próximos de suas realidades estes poderiam ser. O intuito era que vivenciassem o processo e pudessem enxergar as diversas formas do fazer saúde.

A Política Nacional de Promoção da Saúde (PNPS) estabelece em seus temas prioritários a:

Promoção da cultura da paz e de direitos humanos, que compreende promover, articular e mobilizar ações que estimulem a convivência, a solidariedade, o respeito à vida e o fortalecimento de vínculos, para o desenvolvimento de tecnologias sociais que favoreçam a mediação de conflitos, o respeito às diversidades e diferenças de gênero, de orientação sexual e identidade de gênero, entre gerações, étnico-raciais, culturais, territoriais, de classe social e relacionada às pessoas com deficiências e necessidades especiais, garantindo os direitos humanos e as liberdades fundamentais, articulando a RAS [Rede de Atenção à Saúde] com as demais redes de proteção social, produzindo informação qualificada e capaz de gerar intervenções individuais e coletivas, contribuindo para a redução das violências e para a cultura de paz (Brasil, 2014, p.23).

É dentro da Rede de Atenção à Saúde (RAS) que a educação em saúde e o seu processo se instala, no entanto, esta aplicabilidade deve estar em consonância com as demandas do grupo a ser atendido. Os termos a serem utilizados, as vivências a serem compreendidas, as dificuldades encontradas e o conhecimento ali construído, e por fim, uma avaliação sistemática dos resultados obtidos, caso existam.

O tema central do estudo aqui abordado centrava-se na cultura da paz e na promoção da saúde, por meio de categorias. Em cada categoria foram abordadas realidades e vivências. Cada participante foi codificado de um modo para que pudesse ser identificado, conforme suas falas. A letra P seguida de um número representava cada adolescente, a letra $\mathrm{M}$ seguida de um número as mães e a letra $\mathrm{F}$ seguida de um número os pais, tendo, apenas um pai participado da pesquisa.

A primeira categoria elencava a "família" e a representação desta para cada adolescente. Houve por parte de alguns adolescentes a dificuldade de dar significado a este termo. Um significado para além da palavra em si, mas da relação proximal ou não com a palavra no cotidiano. As relações familiares fragmentadas e rompidas demonstram um cenário muitas vezes perverso para o adolescente, mediante a construção de vínculos e os futuros relacionamentos. Sabendo que a constituição do sujeito é uma compreensão da soma do interno e do externo, e que há uma interação cíclica de internalização e externalização frente ao ambiente.

P11: Meu pai e minha mãe. É importante porque faz bem, né.

P1: Minha mãe e minha irmã. Ela me dá estrutura, né.

P5: Não o conheci. Meu pai me abandonou quando eu era pequenininho.

P6: Eu moro longe do meu pai porque ele está preso. Se não era para a gente estar junto. 
As falas retratam aqueles que conseguiram definir, conforme suas concepções o que a família representava para eles. Na maioria das famílias era a mãe que representava a centralidade e o suporte financeiro e afetivo. Como aponta Ramires e Falckes (2018), os vínculos rompidos e fragmentados afetam diretamente o desenvolvimento do adolescente e as suas relações. A forma como este vai se inserir nos grupos, como vai se relacionar no ambiente, como será o processo de interação com a as leis e os valores sociais e como a ausência paterna poderá ou não impactar em suas vidas, mediante o fato de que sentiam falta dos pais, que em alguns casos era desconhecido. Compreender as famílias possibilita entender a capacidade de vinculação dos sujeitos e como estes poderão ser abordados pelos serviços de saúde, educacionais e socioassistenciais.

A categoria "violência" apontava para as vivências de violação de direito e situações de risco com que conviviam. Os conflitos familiares, o preconceito, a exclusão social, a violência policial, o tráfico e o seu funcionamento e o fato de não utilizarem os serviços públicos presentes em seus bairros, como as Unidades Básicas de Saúde (UBS) e os Centros de Referência de Assistência Social (CRAS). A violência é um ciclo que tende a se ampliar se alimentado pela negligência, pela negação de direitos e pela ausência de uma justiça social instituída.



Belga, Silva e Sena (2017) destacam que a violência mantém-se instalada nos territórios e que diversas situações não há um enfrentamento a ela, mas uma atuação repressiva e punitiva que a fortalece. Um ato infracional cometido por um adolescente é apenas um sintoma de uma sociedade que adoece frente às vulnerabilidades e a negação de direitos. Adolescentes expostos a diversos fatores de risco que colocam em questão a sua própria vida.

As relações estabelecidas com o tráfico, como uma forma de renda, se contrapondo ao mercado de trabalho legal, é um exemplo, embora haja a lei de aprendizagem legal. Além, do uso e dependência de álcool e drogas, como a maconha, que são vendidas por eles mesmos. O sistema capitalista coloca em cena os desejos do adolescente, sua condição socioeconômica e o desacesso as oportunidades vivenciando uma exclusão social, que também se configura como uma forma de violência.

Os "serviços disponíveis no território", que elencam outra categoria, foram trabalhados por meio de mapas da cidade em que moram. O intuito era que observassem o espaço e marcassem os serviços presentes, além de contar sobre o bairro e suas características. Unidades Básicas de Saúde (UBS), Centros de Referência de Assistência Social (CRAS), escolas, quadras de esporte, praças e outros espaços que poderiam vir a ser utilizados pelos adolescentes. Embora haja os serviços, o não acesso a estes espaços é constante. Não há um movimento por parte dos serviços para que possam ir ao encontro deste público e os espaços como quadras e praças, perpassam pelo domínio do tráfico e pela presença constante da polícia.

P1: Esse povo tem mó preconceito. Se você for em algum lugar, e a pessoa perguntar onde você mora, e você falar eu moro em tal bairro, já muda até o jeito de te olhar.

P2: Não também. Não tem igualdade. O filho de rico não é tratado igual filho de pobre. Nos faz sentir mais inseguros. É o que deixa nós inseguro. É, nós não tem liberdade.

M4: Eu acho que falta mais lazer. Mais espaço para as crianças e os jovens brincarem. 
M12: Eu acho que lá precisaria de um, assim, de algo assim para estar acompanhando eles, principalmente essa faixa etária de 14 a 16 anos. Ou até entre 11 e 12 anos para cima. No bairro. Porque ali tem lugar que pode montar uma oficina para os adolescentes.

Como aponta Alvarenga (2012), o não acesso aos serviços públicos e as políticas públicas, configura uma negação de direito que tornam a exclusão social e a desigualdade social, ainda maiores. $\mathrm{O}$ adolescente vivencia o preconceito por residir em determinado bairro e isso se acentua quando busca por um emprego. E ainda, os serviços pouco incluem esta população, que só obtém uma atenção mais ampla quando estão em acompanhamento, tendo já cometido o ato infracional.

Quando se fala em promoção e prevenção se pensam em aspectos anteriores a execução da infração. Os serviços públicos devem garantir a estes sujeitos meios de se desenvolverem adequadamente como determina o Estatuto da Criança e do Adolescente (ECA) e de acessarem todos os espaços e, além disso, os profissionais precisam estar preparados para o trabalho com essa população, se lembrando de que esta ação não deve ser limitada e deve ultrapassar diversas fronteiras sociais, econômicas e culturais (Brasil, 1990, Carmo \& Guizardi, 2018).

$\mathrm{Na}$ categoria "direitos e deveres do adolescente" fora trabalhado com os adolescentes o Estatuto da Criança e do Adolescente (ECA), como referência de direitos e proteção integral e os deveres dos adolescentes para com seus familiares e para com o ambiente comunitário. Neste grupo entram em cena questionamentos quanto à ausência de liberdade e as diferenças que segundo eles, existe na atenção e abordagem a pessoas com classes socioeconômicas distintas.

P1: Às vezes você está indo e você nem volta. Você só vai.

P1: Lá na [instituição]... o "bagui" era mais maciço, era mais embaixo. Se tivesse 3 funcionários e você fosse passar perto dos 3 , em que falar pra eles sim senhor três vezes, porque senão, você tomava logo um "pé" na orelha já. E se você ficasse dando muito trampo, os caras tiravam você do convívio e levava lá para a tranca e já era, você tomava um "pau" lá na tranca. Tinha vez que os manos voltavam até sem ar.

P2: A marmita eu bati o garfo tinha logo um "stake" e o negócio nem furou. Cheguei lá no cantinho, juntei, deitei e acordei na madrugada, o "bagui" puxando o meu colchão parecia um gato. Nem coragem de "pá" com o "bagui" eu não tive. Deitei de lado e fiquei quietinho.

P5: Umas ratazanas "monstra".

O processo de educar em saúde também perpassa por uma educação social que garanta aos sujeitos conhecer e compreender as leis que o protegem. O ECA precisa estar acessível a todas as crianças e adolescentes, seja nas escolas, seja em outros espaços que possuem o intuito de garantir e promover os direitos dessa população. Se um adolescente conhece seus direitos, logo conhece também os seus deveres para com a sociedade. Embora demonstrem dificuldades em compreender a lei e obedecê-la, a transgridem, não para serem punidos ou reprimidos, mas para serem compreendidos socialmente, pois retratam um cenário em que as políticas públicas não estão sendo aplicadas corretamente e ativamente, onde os indivíduos se encontram desprotegidos (Brasil, 1990; Dupret, 2002).

As "relações sociais", estabelecidas na quinta categoria, demonstraram como as relações dos adolescentes são construídas tanto dentro do ambiente familiar, como com o ambiente externo como amigos e possíveis parceiras em um relacionamento. Dizem possuir poucos amigos e que as relações com as parceiras eram sempre conturbadas e tidas como difíceis pelos adolescentes. No grupo, apenas um deles estava namorando, porém, boa parte de deles já haviam tido algum relacionamento amoroso.

P8: Amigo é o que está dia-a-dia com você, professor.

P2: Tem que ser um cara que pá. Estar presente nas horas melhores e nas mais baixas também.

Sânchez (2012) aponta que as relações sociais que são construídas pelos adolescentes, mediante uma fase em que vão se inserindo em diversos grupos fora do ambiente familiar, demonstram novas 
características do indivíduo em mediar o seu "eu" e o ambiente ao seu redor. É um processo contínuo de projeção e introjeção a cerca de pensamentos e valores pessoais e grupais.

Na última categoria, abordando a "cultura da paz", os adolescentes puderam estabelecer o quanto todo o processo e as categorias anteriores estavam elencados com a cultura da paz e a promoção da saúde. A cultura da paz, só se torna possível, em processo de educar em saúde e de educar socialmente os sujeitos, visto que ela se dá na mediação dos conflitos, na aplicação efetiva das políticas públicas, no trabalho intersetorial dentro das redes de atenção e no reconhecimento dos indivíduos como atores sociais que devem participar dos processos decisórios, dentro do ambiente democrático e discursivo construído pelo empoderamento, que é o espaço de discurso entre os sujeitos, e pela equidade, que propõe atender a cada indivíduo conforme sua necessidade pessoal (Cabral \& Gothardo, 2014, Mendes, Fernandes \& Sacardo, 2016).

Todos: Foi muito bom estar aqui “fessor" e participar.

P10: No meu grupo anterior era só eu e esse daqui tem mais gente e foi mais legal também.

Todos: A gente aprendeu bastante.

Como salienta Falkenberg et al. (2014) a educação em saúde envolve três segmentos de atores sociais que são necessários para que ela que aconteça. Os profissionais de saúde - mas não somente eles, mediante o conceito de rede intersetorial - devem valorizar a promoção, a prevenção e as práticas curativas. Aos gestores cabe o papel de apoio e suporte aos profissionais. E por fim, o envolvimento da população, que necessita construir seus conhecimentos e aumentar sua autonomia nos cuidados, individual e coletivo. No entanto, é preciso observar o distanciamento presente entre a teoria e prática, pensando no que preveem as políticas e o que de fato é colocado em prática.

A proteção integral, a crianças e adolescentes como estabelecido no ECA (Brasil, 1990), só é possível quando as políticas se tornam efetivas e são aplicadas, de modo que garantam os direitos destes dois grupos e a proteção, como estabelece o Sistema de Garantia de Direitos da Criança e do Adolescente (SGDCA) (Nunes, Ferriani, Malta, Oliveira \& Silva, 2016). Educar em saúde é respeitar as diversidades e reconhecer nos grupos uma fonte de conhecimento, mediada pelas suas relações sociais e pela construção constante dos sujeitos. Dolto (2004) destaca que a adolescência é uma fase do desenvolvimento humano e por isso, deve ser levado em conta o critério de que o adolescente deve ser abordado como um sujeito em desenvolvimento, uma constante transformação, mesmo que não haja um marco sociocultural que a compreenda como uma fase importante neste percurso.

Nenhuma política funciona sem a educação e sem conhecimentos. Zecchin e Andrade (2017) apontam que a educação é libertadora, possibilitando que o indivíduo compreenda o mesmo mundo e suas realidades diversas. Quando os adolescentes abordam uma ausência de liberdade, acentuam além de uma (des)proteção real, uma ausência de conhecimento sobre seus direitos e uma relação de incompreensão sobre as leis e o que elas configuram. A mesma "lei" que pune, falhou na proteção.

A cultura da paz se torna por meio da educação em saúde e da promoção da saúde um dos meios para o enfrentamento a violência e a prevenção dos atos infracionais. A mediação destes conflitos tornase um instrumento essencial, possibilitando o empoderamento, por meio de um espaço dialógico e democrático e considerando os fatores de risco e a vulnerabilidade com que convive esta população. Os Determinantes Sociais em Saúde, também devem ser abordados a fim de que se atendam as necessidades e demandas dos sujeitos, de forma equitativa, compreendendo cada realidade e cada demanda de modo individual, mas ampliando o atendimento e a atenção ao coletivo. $O$ acesso deve ser para todos, conforme o princípio de universalidade, que garante o atendimento independente da raça, credo, sexo, gênero, etnia, condição socioeconômica e nacionalidade.

\section{Considerações finais}


A cultura da paz propõe em sua essência que os discursos permeados de violência, sejam então espaços de discurso para a paz. O alcance desta só é possível quando há o processo de mediação entre os conflitos, a justiça social, a equidade, a universalidade e o empoderamento, visto não como forma de ceder poder, mas como um espaço dialógico de construção de conhecimentos. Uma cultura pacífica possibilita um ambiente saudável e sustentável, buscando investir em políticas públicas justas e na participação ativa da população em cada ação e em que cada debate.

Educar em saúde requer então, um trabalho interdisciplinar e intersetorial, tendo por objetivo um trabalho conjunto entre as políticas públicas. Educar exige uma rede que funcione atentando-se a todas as necessidades dos públicos a serem atendidos, a fim de que, todas as demandas sejam sanadas. Uma rede de proteção é necessária, permitindo dentro dela a construção de conhecimentos e o respeito às diversas vivências e realidades. Todas as ações devem compreender os aspectos socioeconômicos e culturais, possibilitando uma atenção real para esta população.

O estudo apontou que a cultura da paz, pode ser uma norteadora para a prevenção do ato infracional e da violência, mediante o fato de que os adolescentes reconheceram por meio de suas falas e vivências a importância dos conceitos e a necessidade de que se invista em políticas públicas para além da segurança pública, como a saúde, o trânsito e as áreas de esporte e lazer. Quanto ao serviço, apontase a alta demanda e a pouca quantidade de técnicos de referência disponíveis para este atendimento, o que gera um sobrecarga dos profissionais. Outro parâmetro a ser apontado é a preparação dos profissionais para este atendimento e a necessidade de que as políticas de saúde e educação, em especial, trabalhem efetivamente junto a assistência social, que fica sobrecarregada neste acompanhamento. As políticas públicas devem deixar seus espaços físicos e irem até os lares, transformando o território, como um todo, em um espaço de intervenção e participação de todos.

Esta pesquisa apresenta apenas uma pequena realidade, visto o número pequeno de participantes (n. 12), o pequeno número de profissionais atendendo estes adolescentes, a cidade ter uma população de cerca de oitenta mil habitantes apenas e não representar o cenário brasileiro, o que deve servir de impulso para que outras pesquisas surjam dentro do Brasil e em suas diversas realidades. A atenção para a população adolescente em conflito com a lei deve ser tomada a fim de garantir a eles os direitos já estabelecidos pelo Estatuto da Criança e do Adolescente (ECA) e fortalecendo as instituições e profissionais que atendem este público. O conhecimento deve ser uma troca de todos os profissionais, gestores, famílias e indivíduos envolvidos no cumprimento de medidas socioeducativas. A garantia de direitos só é possível num trabalho colaborativo e participativo de todos os envolvidos.

Por fim, a promoção da saúde, que engloba a cultura da paz e a educação em saúde, acontece quando a junção de todos estes conceitos se dá e quando são aplicados de forma colaborativa. Quando se educa em saúde, implementa-se a paz e se promove saúde. A Política Nacional de Promoção da Saúde deve ser fortalecida e envolver a população dentro de um sistema democrático e participativo, a fim de que, se alcancem os Objetivos do Desenvolvimento Sustentável e se tenham ambientes saudáveis e sustentáveis que prezem pela população adolescente em cumprimento de medida socioeducativa e a compreensão das diversas vulnerabilidades que os afetam. E tais mudanças só aconteceram com o incentivo constante às pesquisas que englobem as construções sociais contemporâneas. 


\section{Agradecimentos}

O presente estudo foi realizado com apoio da Coordenação de Aperfeiçoamento de Pessoal de Nível Superior - Brasil (CAPES) - Código de Financiamento 001.

\section{Referências}

Alvarenga, Mirella Souza. (2012). Risco e Vulnerabilidade: razões e implicações para o uso na política nacional de assistência social. Dissertação de Mestrado, Programa de Pós-graduação em Política Social, Universidade Federal do Espírito Santo, Vitória. Recuperado de http://repositorio.ufes.br/handle/10/6497

Belga, Stephanie Marques Moura Franco, Silva, Kênia Lara, \& Sena, Roseni Rosângela de. (2017). Concepções de programas de prevenção à violência e promoção da cultura de paz. Cadernos Saúde Coletiva, 25(2), 177-182. https://doi.org/10.1590/1414-462x201700020215

Brasil. (1990). Estatuto da Criança e do Adolescente (ECA): Lei No . 8.069, de 13 de Julho de 1990. Brasília, ECA.

Brasil. (2004). Política Nacional de Assistência Social (PNAS). Brasília, Ministério do Desenvolvimento Social e Combate à Fome.

Brasil. (2006). Secretaria de Gestão do Trabalho e da Educação na Saúde. Departamento de Gestão e da Regulação do Trabalho em Saúde. Câmara de Regulação do Trabalho em Saúde. Brasília, Ministério da Saúde.

Brasil. (2009). Glossátio temático: gestão do trabalho e da educação na saúde. Brasília, Editora do Ministério da Saúde.

Brasil. (2014). Política Nacional de Promoção da Saúde (PNPS). Portaria n ${ }^{\circ} 2.446$, de 11 de novembro de 2014. Brasília, Ministério da Saúde.

Brasil. (2017). Educação Popular em Saúde. Brasília: Ministério da Saúde, 2014.

Cabral, Raquel \& Gothardo, Josiane. (2014). Princípios da cultura da paz e estratégias de sensibilização em relações públicas no programa de cidades sustentáveis. Razón y Palabra, 88. Recuperado de https://www.redalyc.org/pdf/1995/199532731020.pdf

Carmo, Michelly Eustáquia do, \& Guizardi, Francini Lube. (2018). O conceito de vulnerabilidade e seus sentidos para as políticas públicas de saúde e assistência social. Cadernos de Saúde Pública, 34(3), e00101417. https://doi.org/10.1590/0102-311x00101417

Dolto, Françoise. (2004). A causa dos adolescentes: um projeto humanista para o desenvolvido dos 10-16 anos. Aparecida, Ideias \& Letras.

Dupret, Leila. (2002). Cultura de paz e ações sócio-educativas: desafios para a escola contemporânea. Psicologia Escolar e Educacional, 6(1), 91-96. https://doi.org/10.1590/S1413$\underline{85572002000100013}$ 
Ecco, Idanir \& Nogaro, Arnaldo. (2015). A educação em Paulo Freire como processo de humanização. Educere: XII Congresso Nacional de Educação, 3523-3535. Recuperado de https://educere.bruc.com.br/arquivo/pdf2015/18184 7792.pdf

Falkenberg, Mirian Benites, Mendes, Thais de Paula Lima, Moraes, Eliane Pedrozo de, \& Souza, Elza Maria de. (2014). Educação em saúde e educação na saúde: conceitos e implicações para a saúde coletiva. Ciência \& Saúde Coletiva, 19(3), 847-852. Recuperado de https://doi.org/10.1590/1413$\underline{81232014193.01572013}$

Fonseca, Franciele Fagundes, Sena, Ramony Kris R., Santos, Rocky Lane A. dos, Dias, Orlene Veloso, \& Costa, Simone de Melo. (2013). As vulnerabilidades na infância e adolescência e as políticas públicas brasileiras de intervenção. Revista Paulista de Pediatria,31(2), 258-264. Recuperado de https://doi.org/10.1590/S0103-05822013000200019

Freire, Paulo. (1970). Pedagogia do Oprimido. Rio de Janeiro, Paz e Terra.

Fundo das Nações Unidas para a Infância. (2015). Situação das crianças e adolescentes no Brasil. Brasília, UNICEF.

Gil, Antônio Carlos. (2008). Métodos e técnicas de pesquisa social. São Paulo, Atlas.

Instituto Brasileiro de Geografia e Estatística. (2017). Pesquisa Nacional por Amostra de Domicílios Contínua 2017: Educação. Rio de Janeiro, IBGE.

Machado, Adriana Germano Marega \& Wanderley, Luciana Coutinho Simões. (n.d.). Educação em


https://www.unasus.unifesp.br/biblioteca virtual/esf/2/unidades conteudos/unidade09/unidade09.p df.

Marcondes, Maria Eunice Ribeiro. Proposições metodológicas para o ensino de química: oficinas temáticas para a aprendizagem da ciência e o desenvolvimento da cidadania. (2008). Revista Em Extensão, Uberlândia, 7, 67-77.

Mendes, Rosilda, Fernandez, Juan Carlos Aneiros, \& Sacardo, Daniele Pompei. (2016). Promoção da saúde e participação: abordagens e indagações. Saúde em Debate, 40(108), 190-203. Recuperado de https://dx.doi.org/10.1590/0103-1104-20161080016

Nunes, Marilene Rivany, Ferriani, Maria das Graças Carvalho, Malta, Deborah Carvalho, Oliveira, Wanderlei Abadio de, \& Silva, Marta Angélica Iossi. (2016). Social network of adolescents under probation from the perspective of public health. Revista Brasileira de Enfermagem, 69(2), 298-306. Recuperado de https://dx.doi.org/10.1590/0034-7167.2016690213i

Organização Mundial de Saúde. (1947). Definições básicas: o conceito de saúde. Genebra, OMS.

Ottawa. (1986). Carta de Ottawa: promoção de saúde nos países industrializados/1a Conferência Mundial de Promoção da Saúde. Ottawa.

Ramires, Vera Regina Rohnelt, \& Falcke, Denise. (2018). Fatores de risco e proteção para vínculos familiares no sul do Brasil. Psicologia: teoria e prática,20(1), 126-140. Recuperado de https://dx.doi.org/10.5935/1980-6906/psicologia.v20n1p126-140 
Rasera, Emerson F., \& Japur, Marisa. (2001). Contribuições do pensamento construcionista para o estudo da prática grupal. Psicologia: Reflexão e Crítica, 14(1), 201-209. Recuperado de https://doi.org/10.1590/S0102-79722001000100017

Ribeiro, Kelen Gomes, Aguiar, Janaína Bezerra \& Andrade, Luiz Odorico Monteiro. (2018). Determinantes sociais da saúde: o instituído constitucional no Sistema Único de Saúde. Revista Brasileira em Promoção da Saúde, 31(4), 1-10. Recuperado de https://doi.org/10.5020/18061230.2018.8778

Sánchez, Paula Vanessa (2012). La experiencia vinculante afectiva del sujeto adolescente infractor. Revista Latinoamericana de Ciencias Sociales, Niñez, y Jwventud, 10(1), 453-465. Recuperado de https://www.redalyc.org/articulo.oa?id=773/77323982028

Souza, Marcela Tavares de, Silva, Michelly Dias da, \& Carvalho, Rachel de. (2010). Revisão integrativa: o que é e como fazer. Einstein (São Paulo), 8(1), 102-106. Recuperado de https://doi.org/10.1590/s1679$\underline{45082010 \mathrm{rw} 1134}$

Zechin, Gabriel Bezerra \& Andrade, Maria de Fátima Ramos de. (2017). Sociedade de consumo e o papel da educação. Revista Estudos Aplicados em Educação, 2(3), 75-87. Recuperado de https://doi.org/10.13037/rea-e.vol2n3.4388

\section{Sobre os Autores}

\section{LUCIANO APARECIDO PEREIRA JUNIOR}

(D) ORCID: https://orcid.org/0000-0002-0310-1865

Psicólogo, Doutorando em Promoção de Saúde pela Universidade de Franca/UNIFRAN; Mestre em Promoção de Saúde; Especialista em Psicologia Jurídica e Avaliação Psicológica; Especialista em Psicanálise; Bolsista Capes; Integrante do grupo de pesquisa intitulado "Populações Vulneráveis e Promoção de Saúde", tendo por linha de pesquisa "Vulnerabilidade Social, Tecnologias e Promoção de Saúde" do CNPq.

E-mail: lucianoajuniorpereira@gmail.com

\section{REGINA CÉLIA DE SOUZA BERETTA}

(D) ORCID: https://orcid.org/0000-0003-2817-0805

Assistente Social, Docente e pesquisadora do Programa de Pós-graduação em Promoção de Saúde da Universidade de Franca, Doutora e Mestre em Serviço Social pela Universidade Estadual Paulista Júlio de Mesquita Filho - UNESP/FRANCA, Coordenadora do grupo de pesquisa intitulado "Populações Vulneráveis e Promoção de Saúde", tendo por linha de pesquisa "Vulnerabilidade Social, Tecnologias e Promoção de Saúde" do CNPq.

E-mail: regina.beretta@gmail.com

Submetido: 25 Jul. 2020

Aceito: 14 Ago. 2020 